\title{
Cooccurrence of Yawning and Stereotypic Behaviour in Horses (Equus caballus)
}

\author{
Carole Fureix, ${ }^{1}$ Aleksandra Gorecka-Bruzda, ${ }^{2}$ \\ Emmanuel Gautier, ${ }^{1}$ and Martine Hausberger ${ }^{1}$ \\ ${ }^{1}$ UMR CNRS 6552 Ethologie Animale et Humaine, Université de Rennes 1, Campus de Beaulieu Bâtiment 25, \\ 263 avenue du Général Leclerc, 35042 Rennes Cedex, France \\ ${ }^{2}$ Department of Animal Behaviour, Institute of Genetics and Animal Breeding, Polish Academy of Sciences, \\ Jastrzebiec, Postepu 1, 05552 Wolka Kosowska, Poland
}

Correspondence should be addressed to Carole Fureix, carole.fureix@univ-rennes1.fr

Received 21 January 2011; Accepted 10 March 2011

Academic Editors: E. Addessi and F. Colmenares

Copyright () 2011 Carole Fureix et al. This is an open access article distributed under the Creative Commons Attribution License, which permits unrestricted use, distribution, and reproduction in any medium, provided the original work is properly cited.

\begin{abstract}
Determinants of yawning are still uncertain. As yawning seems to be triggered by stress and emotional contexts, we investigated specific correlates of yawning and stereotypic behaviours in horses. Study 1 investigated correlations in time between yawning and stereotypic behaviour in stereotypic horses from the same facility; study 2, involving riding school horses, investigated the cooccurrence of yawning and stereotypic behaviour at the individual level and in response to environmental factors (feeding time). Results showed that (1) stereotypic horses yawned more than the nonstereotypic horses, (2) yawning increased at the same time periods as stereotypic behaviours did, and (3) yawning frequency was positively correlated with stereotypic behaviour frequencies (study1). Different hypotheses are discussed: direct/indirect causal relationship and other factors susceptible to trigger both yawning and stereotypies. This study, underlining for the first time a cooccurrence of yawning and stereotypic behaviour, opens a promising line of investigation of this puzzling behaviour.
\end{abstract}

\section{Introduction}

A yawn is an involuntary sequence consisting in mammals of mouth opening, deep inspiration, brief apnoea, and slow expiration [1] and is especially frequent in humans and carnivores, for example, $[2,3]$. However, there are just a few behavioural studies on yawning [4], and, although a number of hypotheses attempt to explain why yawning occurs, experimental data are relatively scarce compared to the abundance of theoretical considerations (reviewed by [5]).

Determinants of yawning are still uncertain. The fact that yawning is involved in behavioural state changes is well established, especially in quiet contexts of motor relaxation such as before or just after sleep, see for example, [1-3, 6-8]. However, yawning can also be triggered by stress and emotional contexts (e.g., agonistic social interactions in primates $[1,2]$ potential heat stress in budgerigars [9]). Intracerebroventricular administration of the synthetic adrenocorticotropic hormone, $\mathrm{ACTH}_{1-24}$, increases the frequency of yawning in rats, see for example, [10] and dogs [6]. Cooccurrence of yawning and changes of behaviour associated with stress (e.g., restlessness, lowered posture) has been reported in dogs [11]. Yawning has been proposed to be a "displacement activity" in primates [12], that, is a behavioural pattern apparently irrelevant to the animal's ongoing activity, thought to occur in stressful situations [13]. Clinical approaches to the study of yawning reveal that, among numerous pathologies (such as schizophrenia, multiple sclerosis, epilepsy, and migraine headache), being under stress is conducive of yawning in humans, see for example, [14, 15]. Recently, Reamer et al. [16] exploring correlates of selfdirected behaviour and "abnormal" stereotypic behaviour, prevalent in stress-inducing environments (e.g., [17]) in captive red-capped mangabeys (Cercocebus torquatus torquatus), failed to evidence a relationship between yawning and stereotypic behaviour. Unfortunately, their analysis did not separate yawning from other self-directed behaviours (i.e., self-scratching, self-grooming, and body shaking). 
Here, we investigated specific correlates of yawning and stereotypic behaviours in horses. Horses can be informative models, as a variety of stereotypies have been well described [18] and this species is known to yawn $[1,19]$, a case rare amongst ungulates. We report two studies, both involving equestrian facilities where horses were kept in social isolation (i.e., in boxes) and experienced time-restricted feeding practices, two factors known to trigger stereotypies [20,21]. Social isolation limited the well-known contagious effect of yawning, see for example, [5], and allowed here to study the nonsocial factors potentially impacting yawning occurrence. These two studies are complementary: study 1, considering only stereotypic horses in a facility where all horses were kept under the same conditions (same practices, same food, same sex, mostly same breed), investigated correlations between yawning and stereotypic behaviour and a potential effect of type of work (a factor known to impact emotional reactivity, see for example, $[22,23]$ ) on yawning; study 2 , performed in an ordinary mixed-sex riding school population, investigated potential sex effects and potential cooccurrence of yawning and stereotypic behaviour at the individual level and in response to environmental factors (i.e., feeding time). As both yawning and stereotypical behaviour can be triggered by stress and emotional contexts, here we hypothesized a cooccurrence of these behaviours in horses experiencing stressful practices (social isolation, feeding restriction, see for example, $[20,21])$.

\section{Methods}

All our experiments complied with current French laws related to animal experimentation and were in accordance with the European directive 86/609/CEE. No licence/permit/institutional ethical approval were needed as only behavioural observations were performed. Animal husbandry and care were under the management of the riding school's staff, as this experiment involved only horses "from the field" (no laboratory animals).

2.1. Subjects. We report two experiments: study 1 focused on stereotypic horses from the same facility and study 2 concerned all the horses in three riding schools.

2.1.1. Study 1. Eighty-seven horses (79 French Saddlebred and 8 Anglo-Arabian) were observed at the "Ecole Nationale d'Equitation" (ENE) at Saumur in August 1994. They were all kept under the same conditions in single boxes, were fed pellets ( 3 times a day) and hay (only once, in the morning), had water ad libitum, and were ridden for one hour everyday (see $[24,25]$. Their type of work was dressage $(n=16$ horses), advanced riding school $(n=27)$, show jumping ( $n=22)$, eventing $(n=17)$, or voltige $(n=5)$. They were all geldings and were 6 to 20 years old $(\bar{X}=9.8 \pm 3.4)$.

2.1.2. Study 2. Fifty-nine horses ( 40 French Saddlebreds and 19 diverse breeds and unregistered horses, named "other breeds" hereafter, equally distributed among the centres) from three riding schools ( $n=12,29$, and 18 , respectively) were observed between January and May 2007. Activities and housing conditions were similar in the three riding schools. In all cases, the horses were kept singly in $3 \mathrm{~m} * 3 \mathrm{~m}$ individual straw-bedded boxes. Each box was cleaned once a day (in the morning) and was equipped with an automatic drinker. Animals were fed industrial pellets three times a day, and hay was provided ad libitum once a day. Horses worked in riding lessons for 4-12 hours a week, with at least 1 free day each week (closing day). Riding lessons involved children and teenagers and were related mainly to indoor (instruction) and outdoor activities, including a few competition activities. This sample included both geldings (44) and mares (15). They were 5 -to 20 -year old $(\bar{X}=12 \pm 3.5)$.

2.2. Behavioural Observations. In both studies, each horse was observed in its box using a focal sampling method [26]; all behaviours of the focal animal were recorded continuously during $5 \mathrm{~min}$ sessions. Only one horse was observed at a time (i.e., one focal animal), and horses were randomly assigned to observations (i.e., neighbours were not observed in succession), in order to limit potential contagious effects of yawning, well-known in several species, see for example, [5].

2.2.1. Study 1. The subjects were of the same sex, most of the same breed, and all were kept under the same conditions (housing and feeding practices). They were observed outside feeding times, more often in the afternoon ( 1 to $4 \mathrm{p} . \mathrm{m}$. and 5 to 7 p.m.; 514 of the 943 focus observations, on average $29.54 \pm 5.84 \mathrm{~min}$ observation/horse) than in the morning (8 to 11 a.m.; $283 / 943$ focused, $\bar{X}=16.84 \pm 3.42 \mathrm{~min}$ observation/horse) and before meals (146 focused). Stereotypic behaviour did not increase before meals, which may be due to the fact that all the horses were fed simultaneously by an automatic feeder (general to the whole facility) (Hausberger, unpublished data). Each horse was observed during 10 to 12 5 min sessions, that is, yielding 50 -to 60 -minute observation per horse (mean: $54.20 \pm 2.74 \mathrm{~min}$ per horse). The same observer (E.Gautier) recorded all the observations. The observation of a given horse changed every day following a rotation schedule (thus if one horse was observed from 05:00 p.m. to 05:05 p.m. on day 1, it was observed between 05:05 p.m. to 05:10 p.m. on day 2 , etc).

2.2.2. Study 2. Observations were made during three periods: in the morning between 9 and 11 a.m., in the afternoon between 2 and 5 p.m., and half an hour before meal times (i.e., between 6.30-7.30 a.m., 11.30-12 a.m., or 5.30-6 p.m., according to school schedules). The fact that food was distributed manually created a favourable situation for observing repetitive movements, see for example, $[18,21]$. Each horse was observed during 6 sessions (2 sessions per time period $=30 \mathrm{~min}$ total/horse). The same observer (C.Fureix) made all the observations.

Although we recorded all behavioural patterns in both studies, here we focused precisely on yawning and stereotypic behaviour. The stereotypic behaviours observed (Table 1) have been described previously and all consist in functionless 
TABLe 1: Type (oral/motor), name, and description of stereotypic behaviours recorded, adapted from [18, 25].

\begin{tabular}{|c|c|c|}
\hline Type & Name & Description \\
\hline \multirow{4}{*}{ Oral } & Cribbing & $\begin{array}{l}\text { The horse grasps a fixed object with its incisors, pulls back, and draws air into its oesophagus } \\
\text { while emitting a characteristic pharyngeal grunt. }\end{array}$ \\
\hline & Lip play & $\begin{array}{l}\text { The horse moves its upper lip up and down without making contact with an object, or the horse } \\
\text { smacks its lips together. }\end{array}$ \\
\hline & Tongue play & The horse sticks out its tongue and twists it in the air. \\
\hline & Lip or teeth rubbing & The horse rubs its upper lip or its upper teeth repetitively against the box wall. \\
\hline \multirow{2}{*}{ Motor } & Head shaking and nodding & The horse bobs repetitively its head up and down or tosses its head in recurrent and sudden bouts. \\
\hline & Weaving & The horse sways laterally, moving its head, neck, forequarters, and sometimes hindquarters. \\
\hline
\end{tabular}

TABle 2: Percentage of horses displaying each type of stereotypic behaviours according to the site (ENE and riding schools).

\begin{tabular}{lcc}
\hline Stereotypic behaviour & ENE $(N=87)$ & Riding schools $(N=59)$ \\
\hline Cribbing & $18 \%$ & $2 \%$ \\
Tongue play & $97 \%$ & $0 \%$ \\
Lip play & $0 \%$ & $22 \%$ \\
Lip and teeth rubbing & $0 \%$ & $8 \%$ \\
Repetitive wall licking & $78 \%$ & $14 \%$ \\
Repetitive feeder & $51 \%$ & $27 \%$ \\
licking/biting & & \\
Repetitive object & $48 \%$ & $22 \%$ \\
licking/biting & $79 \%$ & $27 \%$ \\
Head shaking/nodding & $21 \%$ & $7 \%$ \\
Weaving & & \\
\hline
\end{tabular}

repetitive movements (review in [18]). In addition to these "classical" stereotypies, we recorded repetitive licking/biting (walls, grids, feeder...) as additional abnormal repetitive behaviours [25].

2.3. Data and Statistical Analyses. In all cases, data analysed were frequencies (per min) of yawning and stereotypic behaviours, and horses were also binary classified for the analyses as "performing that behaviour at least once"/ "never observed performing that behaviour" (e.g., yawning/ nonyawning horses). Types of stereotypic behaviour were analysed both separately and by pooling them into oral (i.e., tongue play, repetitive wall, feeder, object licking/ biting and cribbing, see also Table 1) and motor (i.e., head shaking/nodding and weaving) categories. Statistical analyses were conducted using Statistica 7.1 software, and the accepted $P$ level was .05 (two-tailed tests). As data were not normally distributed, we used nonparametric statistical tests [27]: Mann-Whitney $U$ tests to compare behavioural frequencies and age between two independent groups (e.g., yawning/nonyawning horses, stereotypic/nonstereotypic horses,...), chi-square and Fisher tests to compare proportions in relation to the classification of a second variable (e.g., stereotypic/nonstereotypic horses) between two independent groups (e.g., yawning/nonyawning horses) Friedman and Wilcoxon tests to compare behavioural frequencies between observation periods, and Spearman correlation tests to correlate behavioural frequencies together (e.g., yawning and stereotypic behaviour) and with age.

Study 1 horses only differed by type of work that has been shown to influence the prevalence and types of stereotypies [25] and emotional reactivity [23]. Therefore, the relationship between type of work and stereotypic behaviour has not been developed hereafter, but we investigated a potential type-of-work effect on yawning frequencies. Study 2 investigated, in addition to the factors tested in study 1 , the effects of (1) observation period (i.e., outside feeding time in the morning and the afternoon, and $30 \mathrm{~min}$ before meals, as the preprandial period is favourable for observing repetitive movements, e.g., [21]) and (2) sex-related differences (geldings/mares) on occurrences of yawning and of stereotypies. No type-of-work effect could be tested here, as all horses worked in riding lessons.

\section{Results}

3.1. Study 1. Thirty-one percent of the horses (27/87) yawned at least once (mean \pm standard error $X=0.02 \pm 0.05$ times/min/horse, $0-0.36$ ). No differences appeared according to age, breed, or type of work on yawning occurrence $(P>$ .05 in all cases, Table 3 ).

Stereotypic behaviours were observed $0.45 \pm 0.46$ times per $\min (0.02-3.22$ time/min) and consisted of tongue play (84 horses), head shaking and nodding (69 horses), repetitive wall (68 horses), feeder ( 44 horses), and object (42 horses) licking/biting, while weaving and cribbing were less represented (18 and 16 horses, respectively) (Table 2). Most horses $(N=84 / 87)$ performed two or more types of stereotypic behaviours.

A clear relationship appeared between yawning and stereotypic behaviours:

(1) "yawners" (observed yawning at least once) performed stereotypic behaviours more often than "nonyawners" did (Mann Whitney test, $N_{\mathrm{Y}}=27, N_{\text {Non Y }}=60, X_{\mathrm{Y}}=$ $0.65 \pm 0.44, X_{\text {Non } Y}=0.36 \pm 0.44, U=389.50, P<.001$, Figure $1(\mathrm{a}))$. This was still true when oral $(U=424.00$, $P<.001$, Figure $1(\mathrm{~b}))$ and motor $(U=501.00, P<$ .005 , Figure 1(c)) stereotypic behaviours were considered separately (see Table 4 for detailed analyses according to the type of stereotypic behaviour). 


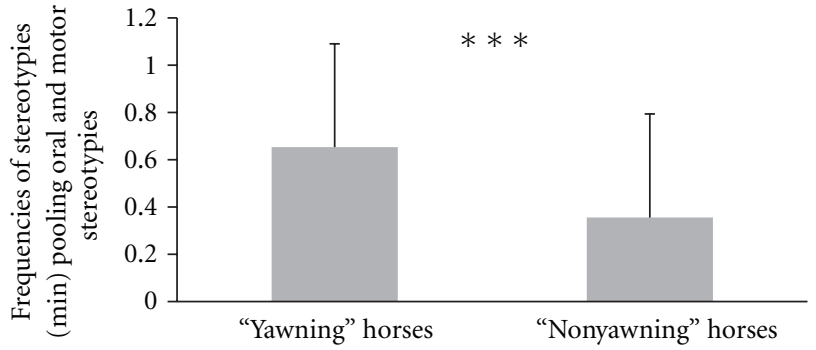

(a)

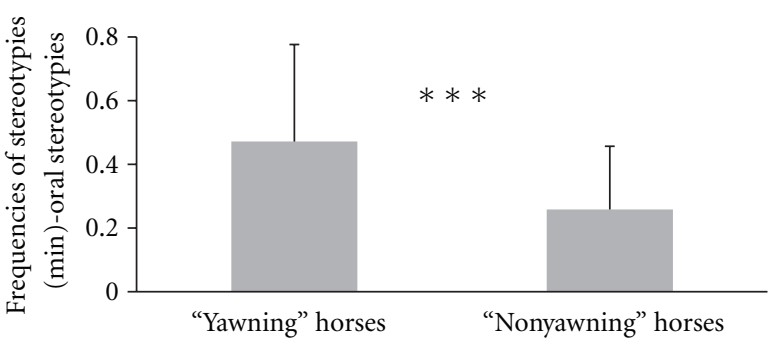

(b)

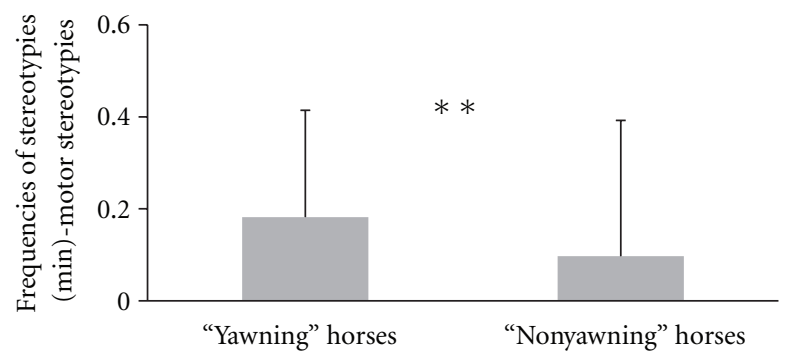

(c)

FIgURE 1: Frequencies of stereotypic behaviours (per minute) for ENE horses (a) pooled oral and motor stereotypic behaviour data, (b) oral stereotypic behaviour data only, and (c) motor stereotypic behaviour only data, for "yawning" horses (i.e., that yawned at least once) and "nonyawning" horses (i.e., never observed yawning). Oral stereotypic behaviours were tongue play, repetitive wall, feeder, and object licking/biting and cribbing. Motor stereotypic behaviours were head shaking/nodding and weaving. "Yawning" horses performed stereotypic behaviours, both oral and motor, more often than "nonyawning" horses. Mann Whitney tests, ${ }^{* *} P<.01,{ }^{* * *} P<.001$.

TABLE 3: Absence of age, sex, breed, and type-of-work effects on yawning (presence/absence and frequency) for ENE and riding schools horses. $P>.05$ in all cases. No sex effect could be tested in study 1 (only geldings) and no type-of-work effect could be tested in study 2 (only one type: riding lessons).

\begin{tabular}{lcc}
\hline & ENE (study 1) & Riding schools (study 2) \\
\hline Age & & Mann Whitney, $U=358.00$ \\
Presence/absence of yawning & Mann Whitney, $U=746.50$ & Spearman correlation, $r_{s}=0.09$ \\
Frequency of yawning & Spearman correlation, $r_{s}=-0.08$ & Chi square, $\chi_{1}^{2}=0.05$ \\
Sex & - & Mann Whitney, $U=320.50$ \\
Presence/absence of yawning & - & Chi square, $\chi_{1}^{2}=0.02$ \\
Frequency of yawning & Chi square, $\chi_{1}^{2}=1.41$ & Mann Whitney, $U=370.50$ \\
Breed & Mann Whitney, $U=255.50$ & - \\
Presence/absence of yawning & & - \\
Frequency of yawning & Chi square, $\chi_{4}^{2}=2.34$ & - \\
Presence/absence of yawning & Kruskall Wallis, $H(4,87)=2.56$ & \\
Frequency of yawning & &
\end{tabular}

(2) Very striking is the finding that the frequency of yawning was correlated with the frequency of all stereotypic behavioural patterns (Spearman correlation test, $N=87$, $r_{s}=0.44, P<.001$, Figure $\left.2(\mathrm{a})\right)$, as well as with oral $\left(r_{s}=0.39, P<.001\right.$, Figure $\left.2(\mathrm{~b})\right)$ and motor $\left(r_{s}\right.$ all $=0.32$, $P<.005$, Figure 2(c)) stereotypic behaviours (see Table 4 for detailed analysis).

(3) Cooccurrence was observed as both yawning and stereotypic behaviours were more frequent in the afternoon (no hay) than in the morning (hay) (Wilcoxon tests, $N=87$, yawning: $X_{\mathrm{Aft}}=0.02 \pm 0.06, X_{\mathrm{Mor}}=0.01 \pm 0.06, Z=2.41$,
$P<.05$; stereotypies: $X_{\text {Aft }}=0.59 \pm 0.54, X_{\text {Mor }}=0.24 \pm 0.41$, $Z=5.43, P<.001$ ) (see Table 4 for detailed analysis).

3.2. Study 2. No differences were observed between riding schools concerning yawning presence/absence (chi-square test, $\chi_{2}^{2}=0.90, P>.05$ ) or yawning frequencies (Kruskall Wallis test, $\left.H_{(2,59)}=0.65, P>.05\right)$; therefore, data for all riding schools were pooled.

Thirty-six percent of the horses yawned at least once $(\bar{X}=0.05 \pm 0.08$ times per min/horse, $0-0.33)$. Neither age, 


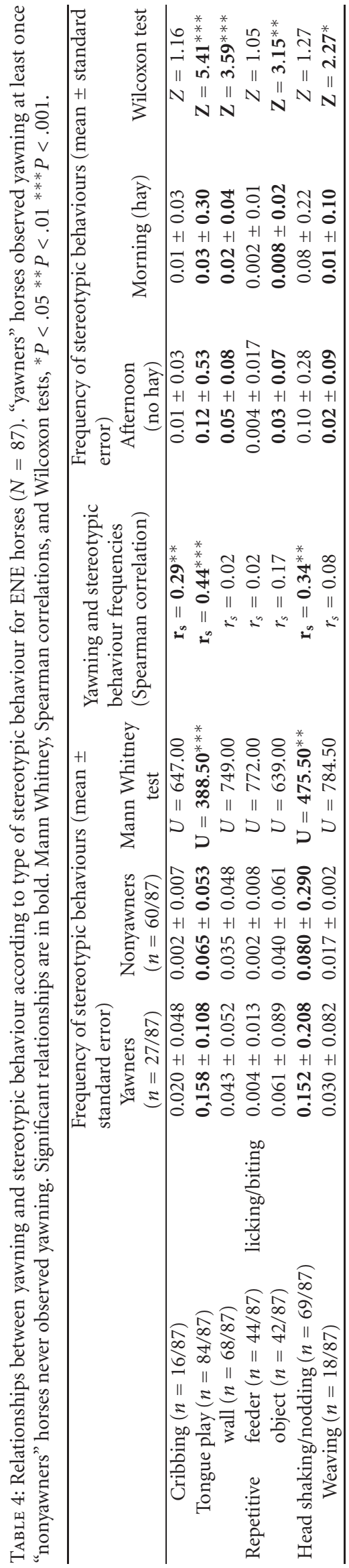




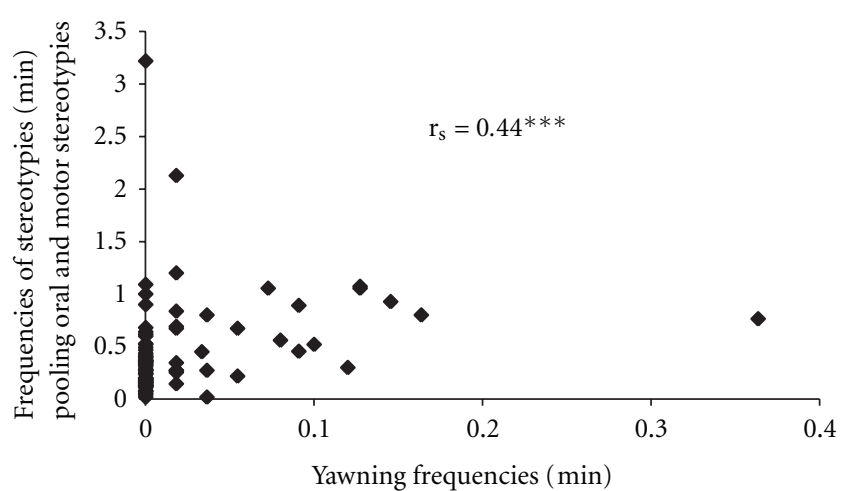

(a)

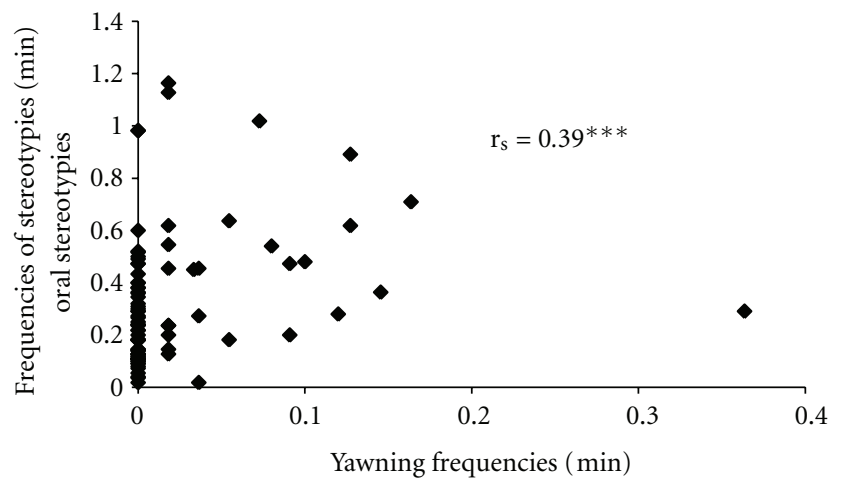

(b)

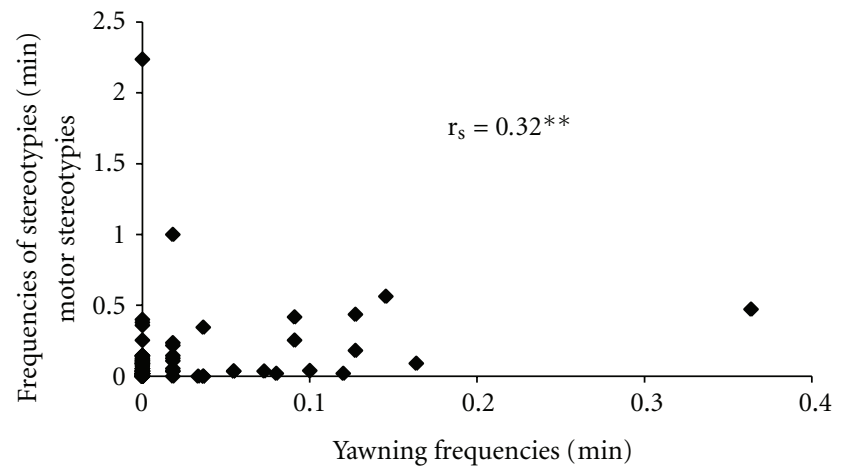

(c)

FIGURE 2: Frequencies of stereotypic behaviours (per minute) in relation to yawning frequency for ENE horses. (a) pooled oral and motor stereotypic behaviours, (b) oral stereotypies, and (c) motor stereotypies for the 50-60 minutes focal observations. Oral stereotypic behaviours: tongue play, repetitive wall, feeder, and object licking/biting, and cribbing; motor stereotypic behaviours: head shaking/nodding and weaving. The more frequently the horses yawned, the more frequently the stereotypic behaviours were displayed. Spearman correlation tests, $N=59, * * P<.01, * * * P<.001$.

sex nor breed significantly influenced the presence or the frequency of yawning $(P>.05$ in all cases, Table 3$)$.

Stereotypic behaviours were observed in $66 \%$ of the horses $(39 / 59, X=0.14 \pm 0.21$ times per min, range: $0-0.77$; oral: $X=0.08 \pm 0.13$ times per $\mathrm{min} /$ horse; motor: $X=$ $0.06 \pm 0.15$ times per $\mathrm{min} /$ horse) which were distributed as follows: head shaking and nodding (16 horses), repetitive feeder (16 horses) or wall ( 8 horses) licking, lip play (13 horses), repetitive object biting (13 horses), weaving (4 horses), lip or teeth rubbing ( 4 horses), and cribbing (1 horse) (Table 2). Twenty horses (34\%) presented more than one stereotypic behaviour. No difference appeared according to age (presence/absence: Mann Whitney test, $N_{\text {(At least } 1 \text { stereotypy) }}=39, N_{\text {(No stereotypy })}=20, X_{\mathrm{S}}=12.26 \pm$ 3.71 years, $X_{\mathrm{NS}}=10.95 \pm 2.93$ years, $U=311.50, P>.05$; the frequency of occurrence: Spearman correlation test, $N=59$, $r_{s}=0.12, P>.05$ ) nor sex (presence/absence: chi square test, 10/15 mares, 29/44 geldings, $\chi_{1}^{2}=0.003, P>.05$; frequency of occurrence: Mann Whitney test, $N_{\mathrm{M}}=15, N_{\mathrm{G}}=44$, $\left.X_{\mathrm{M}}=0.09 \pm 0.10, X_{\mathrm{G}}=0.16 \pm 0.23, U=308.00, P>.05\right)$.

Cooccurrence of yawning and stereotypic behaviours could be observed.

(1) More "yawners" than nonyawners were also "stereotypic" (Fisher test, $P<.02$, Figure 3 ), but this relationship did not reach significance when testing each stereotypic behavioural pattern separately (Fisher tests, $P>.05$ in all cases).

(2) Both yawning and stereotypies occurred more often before meals than outside feeding times (Friedman tests, yawning $_{(59,2)}=22.53$, Figure $4(\mathrm{a})$; stereotypical behav$\operatorname{iours}_{(59,2)}=22.16$, Figure $\left.4(\mathrm{~b})\right)$, including oral $\left(X_{\mathrm{BefM}}=\right.$ $0.13 \pm 0.25, X_{\text {Mor }}=0.04 \pm 0.14, X_{\text {Aft }}=0.05 \pm 0.16$, Friedman test $(59,2)=14.59, P<.001)$ and motor stereotypic behaviours $\left(X_{\mathrm{BefM}}=0.16 \pm 0.39, X_{\mathrm{Mor}}=0.02 \pm 0.16, X_{\mathrm{Aft}}=\right.$ $0.01 \pm 0.08$, Friedman test $(59,2)=22.54, P<.001)$ (Table 5 for detailed analyses according to the type of stereotypic behaviour).

However, in these horses, no correlations between frequencies of yawning and stereotypic behaviours (Spearman correlation test; $\left.N=59, r_{s}=0.15, P>.05\right)$ could be evidenced, even when oral $\left(r_{\mathrm{s} \text { all oral }}=0.14 ; P>.05\right)$ and motor $\left(r_{s}=0.14 ; P>.05\right)$ stereotypies and each type of stereotypic behaviour $\left(r_{s}=-0.02\right.$ to $0.23, P>.05$ in all cases) were considered separately.

Comparisons between sites (ENE versus riding schools) revealed no significant influence of site either on yawning presence (Chi-square test, ENE: 27/87, RS: $21 / 59, \chi_{1}^{2}=0.33$, $P>.05$ ) or on the frequency of occurrence (Mann Whitney 


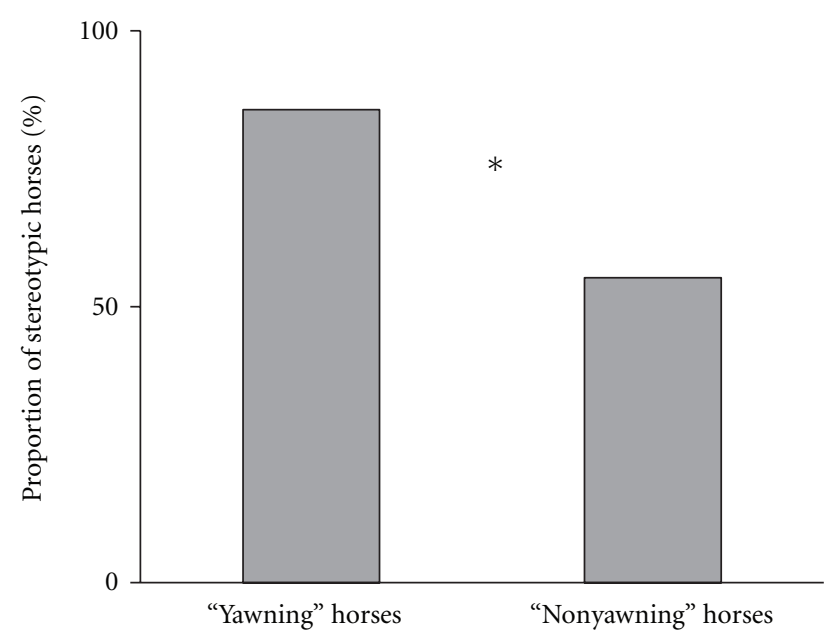

Figure 3: Proportions of "stereotypic" riding school horses (i.e., that displayed at least once a stereotypic behaviour) between "yawning" horses (i.e., that yawned at least once) and "nonyawning" horses (i.e., that were never observed yawning). Yawning horses were more prone to display a stereotypic behaviour at least once than were nonyawning horses. Fisher test, ${ }^{*} P<.05$.

test, $X_{\mathrm{ENE}}=0.02 \pm 0.05, X_{\mathrm{RS}}=0.04 \pm 0.08, U=2334$, $P>.05)$.

\section{Discussion}

We observed in horses clear cooccurrences of yawning and stereotypic behaviours in two different situations: a oneplace one-sex situation and ordinary mixed-sex riding school populations. Horses presenting stereotypic behaviour yawned more than the nonstereotypic horses. Yawning increased at the same time periods as stereotypic behaviours did, and its frequency was, in the first study, correlated with stereotypic behaviour frequencies: the more frequent their stereotypic behaviours were displayed, the more frequently the horses yawned. Interestingly, type of stereotypic behaviour (oral/motor) did not influence this correlation. Frequencies of occurrence as well as proportions of horses yawning did not differ between the two studies. No effects of age or of sex could be evidenced for either type of stereotypic behaviour.

Our results underline for the very first time a clear relationship between yawning and behavioural disorders (i.e., stereotypies), focusing on spontaneous expression of these behaviours and using an original model, the horse. To our knowledge, only one previous study broached this issue, but it failed to evidence correlates between yawning and stereotypic behaviours in captive red-capped mangabeys [16]. However, Reamer et al's analysis did not separate yawning from other self-directed behaviours (SDBs), and the authors argued that the hygienic function of some of these SDBs (e.g., self-grooming) could have masked variations in rates of SDB linked to emotional states.

Three lines of hypotheses can be considered to explain the relationship between yawning and stereotypic behaviours in our study. Firstly, a direct causal relationship (i.e., one behaviour triggers the other) may be involved. However, the kind of physiological and/or behavioural mechanism underlying such a direct causal relationship between yawning and stereotypies is not clear and remains to be investigated. Moreover, temporal analysis of our data revealed that yawning did not occur more frequently after or before stereotypic behaviours than after or before other behaviours (Fureix et al., unpublished data).

More interesting is the hypothesis that one of the behaviours may trigger the other indirectly through another factor (i.e., an indirect causal relationship). Interestingly, stereotypic horses have been reported to lie down and sleep less than nonstereotypic horses, maybe because of being focused on their stereotypic behaviours [24]. This may induce tiredness (because of less sleep and more energy spent performing repetitive movements), and drowsiness is a factor commonly reported to trigger yawning, see for example, [1$3,6-8]$. Moreover, according to the brain cooling hypothesis, excessive yawning appears to be symptomatic of conditions that increase brain and/or core temperature (see [14]), and these conditions include sleep deprivation. Additionally, the energy spent in repetitive movements and/or mental activity in relation to stereotypic behaviours may promote an increase in brain temperature in stereotypic horses, which could trigger compensatory yawning according to A.C. Gallup and G.G. Gallup's [14] brain cooling hypothesis.

The third hypothesis predicts that other factors, among which gastrointestinal dysfunctions (common in domestic ungulates [28]) can be mentioned, trigger both yawning and stereotypies. Indeed, gastric diseases can be accompanied by yawning [4] and cooccurrence of stereotypy performance and gastrointestinal acidity has led to suggestions that oral stereotypic behaviours are a response to gut health (perhaps having some beneficial effects, for instance, by generating saliva which helps to rectify gastrointestinal $\mathrm{pH}$ ) [28]. However, the relationship we observed between yawning and stereotypic behaviours seems to be independent of type of stereotypy (i.e., oral but also motor), and all but one (in ENE horses) or two (in riding school horses) stereotypic behaviours were linked with or increased at the same time periods as yawning. Thus these results suggest that, even if possibly involved, gastrointestinal dysfunctions are not the only mechanism at stake.

Interestingly, the riding school horses yawned and displayed stereotypic behaviours more often before meals than outside feeding periods, in accordance with previous studies focusing independently on yawning (e.g., $[3,4,15,29]$ ) or stereotypic behaviour occurrences, see for example, [28]. Physiological factors such as hunger can trigger yawning (i.e., the increase of yawning at the beginning of diabetics' hypoglycaemia, similar to the feeling of hunger in nondiabetics [15]). However, feeding is probably one of the major events in the day of captive animals, and the importance of psychological factors (e.g., frustration) has been suggested by Mason (1971, cited in [30] who observed that cortisol increased in monkeys when they were not given food (...while their neighbours were) and that this response disappeared when they were given nonnutritive pellets of the same appearance and flavour as their food. 


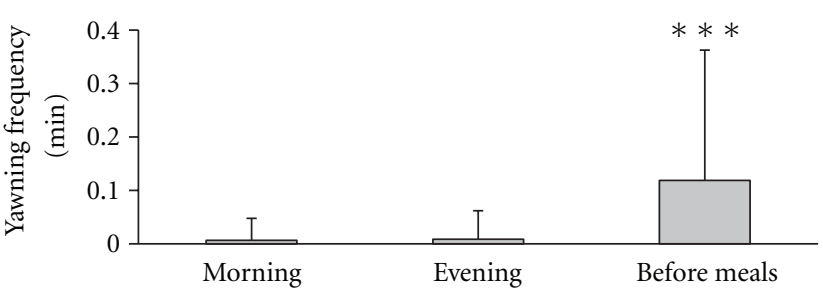

(a)

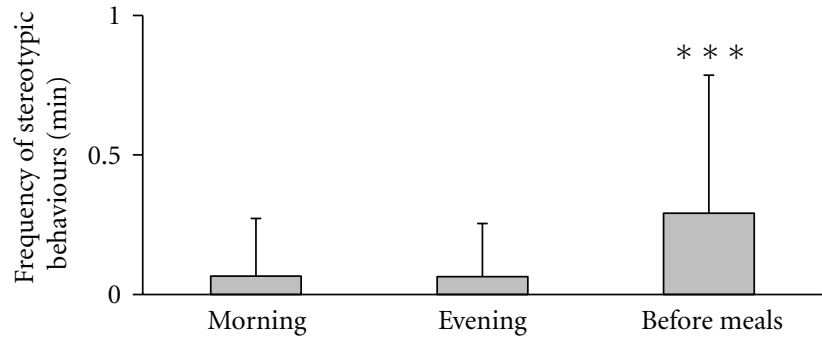

(b)

FIGURE 4: Yawning frequency (per minute) (a) and stereotypic behaviour frequency (per minute, pooled data for oral and motor stereotypic behaviours) (b) in riding school horses. Horses yawned and displayed stereotypic behaviours more often half an hour before meals (i.e., 6.307.30 a.m., 11.30-12.00 a.m., or 5.30-6.00 p.m.) than during either the morning (9-11 a.m.) or the afternoon (2-5 p.m.) periods. Friedman and Wilcoxon tests, ${ }^{* * *} P<.001$.

TABLE 5: Frequencies of each type of stereotypic behaviour in relation to the period of the day (before meals, morning, and afternoon) for riding school horses $(N=59)$. Significant relationships are in bold, and behavioural frequencies with different letters differ significantly. Lip and teeth rubbing, cribbing, and weaving were not analysed here as these behaviours were performed, respectively, by only 4 , 1 , and 4 horses. Friedman and Wilcoxon tests, ${ }^{* *} P<.01{ }^{* * *} P<.001$.

\begin{tabular}{|c|c|c|c|c|c|c|}
\hline & \multicolumn{3}{|c|}{ Frequency of stereotypic behaviours (mean \pm standard error) } & \multirow[t]{2}{*}{ Friedman test } \\
\hline & & & Before meals & Morning & Afternoon & \\
\hline \multicolumn{3}{|c|}{ Lip play $(n=13 / 59)$} & $0.05 \pm 0.11^{\mathrm{a}}$ & $0.003 \pm 0.03^{b}$ & $0.02 \pm 0.10^{\mathrm{b}}$ & $19.58^{* * *}$ \\
\hline \multicolumn{3}{|c|}{ wall $(n=8 / 59)$} & $0.01 \pm 0.05^{\mathrm{a}}$ & $0.01 \pm 0.03^{\mathrm{a}}$ & $0.01 \pm 0.05^{\mathrm{a}}$ & 0.07 \\
\hline \multirow[t]{2}{*}{ Repetitive } & feeder $(n=16 / 59)$ & licking/biting & $0.01 \pm 0.05^{\mathrm{a}}$ & $0.03 \pm 0.12^{\mathrm{a}}$ & $0.02 \pm 0.06^{\mathrm{a}}$ & 0.78 \\
\hline & object $(n=13 / 59)$ & & $0.03 \pm 0.08^{\mathrm{a}}$ & $0.003 \pm 0.03^{b}$ & $0.008 \pm 0.04^{b}$ & $11.44^{* *}$ \\
\hline \multicolumn{3}{|c|}{ Head shaking/nodding $(n=16 / 59)$} & $0.12 \pm 0.32^{\mathrm{a}}$ & $0.002 \pm 0.01^{b}$ & $0.002 \pm 0.01^{b}$ & $25.76^{* * *}$ \\
\hline
\end{tabular}

Moreover, the frequencies of the stereotypic behaviours of the ENE horses did not increase before meals. This may be due to the fact that they were all given exactly the same food, at the same time, by an automatic feeder, thus creating a less frustrating situation (i.e., no delay between the first and the last horse fed in the stable) compared to the manual distribution of food in the riding schools. However, one has to note that cooccurrence between yawning and stereotypic behaviours was observed outside meal periods and both were more frequent in the afternoon than in the morning. Interestingly, no hay was given to the horses in the afternoon (while they were fed hay in the morning), suggesting that these horses may be more frustrated in the afternoon.

Here, following the third hypothesis, we argue that frustration may be a common factor triggering both yawning and stereotypic behaviours. Researchers have proposed that yawning is a "displacement activity", see for example, [12, 16], known to occur in frustration-inducing situations [13], and frustration is the "one common factor to all conditions in which stereotypies develop". [31] Moreover, motivational explanations of stereotypic behaviours argue that, if sustained, displacement activities resulting from frustrationrelated stress can develop into stereotypies (e.g., the development of pacing by food-frustrated hens repeatedly trying to escape their cage [32]). Clearly our aim here is not to argue that yawning is a stereotypic behaviour, but that individual susceptibility to frustration may be a common mechanism for explaining the cooccurrence of these behaviours in horses kept under suboptimal environmental conditions (confinement, social isolation and time-restricted feeding practices).

Moreover, the horses studied here both yawned and displayed stereotypic behaviours more often than did feral horses and horses kept under natural conditions studied in a comparative approach (Górecka et al., in prep). In addition to the clear relationship between yawning and stereotypies, our results reinforce the importance of exploring yawning in relation to welfare issues.

In our study, yawning and stereotypic behaviour frequencies were not significantly influenced by the horses' sex, age, or breed. Yet yawning has been reported as more frequent in males and in adult than younger males in nonhuman primates, and this has been related to androgen (testosterone) levels and sexual maturity $[33,34]$. The higher prevalence in sexually mature males is also supported by another study including stallions (Górecka et al., in prep). Thus, the fact that all the males we studied here were adult geldings (i.e., castrated horses) may explain the lack of sex- and agerelated differences in our study and reinforces the idea that testosterone levels may be involved.

In conclusion, given the current state of knowledge, yawning has a complex causation, and the relationship between yawning and stereotypies observed in horses offers a promising line of investigation. Amongst the challenging issues is the general problem of distinguishing between an "abnormal" behaviour (e.g., displacement activity) and the 
same behaviour pattern in a "normal" pattern $[12,13]$. Thus, it would be interesting to study more precisely the morphology of yawning according to context (e.g., preprandial/outside feeding time, displayed by stereotypic/nonstereotypic animals), by taking into account yawning duration and interoccurrence latencies, preceding/following behaviours, and presence/absence of stretching, in association with other postural elements. Such an approach should help to identify different kinds of yawning (at rest, emotional...) and potentially different functions of this puzzling behaviour.

\section{Acknowledgments}

This study was accomplished thanks to the permission of Lieutenant Colonel d'Hérouville and the help of P. Galloux at the "Ecole Nationale d'Equitation de Saumur". The authors thank the directors of the three riding schools, M. S. Gicqueau, Ms C. Dufeu, and M. F. Reyé, and all their staffs for allowing us to work with their horses and for their help and understanding. They are grateful to Christophe Lunel for his help in data analysis and Dr Ann Cloarec for correcting the English of this manuscript. This work was supported by a grant from the Caisse Centrale de la Mutualité Sociale Agricole.

\section{References}

[1] O. Walusinski and B. L. Deputte, "Le bâillement: phylogenèse, éthologie, nosogénie," Revue Neurologique, vol. 160, no. 11, pp. 1011-1021, 2004.

[2] B. L. Deputte, "Ethological study of yawning in primates. 1. Quantitative analysis and study of causation in two species of old world monkeys (Cercocebus albigena and Macaca fascicularis)," Ethology, vol. 98, no. 3-4, pp. 221-245, 1994.

[3] J. Barbizet, "Yawning," Journal of Neurology, Neurosurgery, and Psychiatry, vol. 21, no. 3, pp. 203-209, 1958.

[4] R. Baenninger, "Some comparative aspects of yawning in betta-splendens, homo-sapiens, panthera-leo and papiosphinx," Journal of Comparative Psychology, vol. 101, pp. 349354, 1987.

[5] A. G. Guggisberg, J. Mathis, A. Schnider, and C. W. Hess, "Why do we yawn?" Neuroscience and Biobehavioral Reviews, vol. 34, no. 8, pp. 1267-1276, 2010.

[6] M. Greco, R. Baenninger, and J. Govern, "On the context of yawning-when, where and why," Psychological Record, vol. 43, pp. 175-183, 1993.

[7] F. Giganti, M. J. Hayes, G. Cioni, and P. Salzarulo, "Yawning frequency and distribution in preterm and near term infants assessed throughout 24-h recordings," Infant Behavior and Development, vol. 30, no. 4, pp. 641-647, 2007.

[8] I. Zilli, F. Giganti, and P. Salzarulo, "Yawning in morning and evening types," Physiology and Behavior, vol. 91, no. 2-3, pp. 218-222, 2007.

[9] L. de Castro Siqueira, "Yawning and thermoregulation in budgerigars: lack of support from results," Animal Behaviour, vol. 78, no. 6, pp. E1-E2, 2009.

[10] J. R. Eguibar, M. Barajas, and A. Moyaho, "Genotype-dependent effect of ACTH on grooming and yawning in two inbred strains of rats," Neuropeptides, vol. 38, no. 5, pp. 283-288, 2004.
[11] B. Beerda, M. B. H. Schilder, J. A. R. A. M. Van Hooff, H. W. De Vries, and J. A. Mol, "Behavioural, saliva cortisol and heart rate responses to different types of stimuli in dogs," Applied Animal Behaviour Science, vol. 58, no. 3-4, pp. 365-381, 1998.

[12] D. Maestripieri, G. Schino, F. Aureli, and A. Troisi, "A modest proposal: displacement activities as an indicator of emotions in primates," Animal Behaviour, vol. 44, no. 5, pp. 967-979, 1992.

[13] N. Tinbergen, "Derived activities; their causation, biological significance, origin, and emancipation during evolution," The Quarterly Review of Biology, vol. 27, no. 1, pp. 1-32, 1952.

[14] A. C. Gallup and G. G. Gallup, "Yawning and thermoregulation," Physiology and Behavior, vol. 95, no. 1-2, pp. 10-16, 2008.

[15] O. Walusinski, "Yawning in diseases," European Neurology, vol. 62, no. 3, pp. 180-187, 2009.

[16] L. Reamer, Z. Tooze, C. Coulson, and S. Semple, "Correlates of self-directed and stereotypic behaviours in captive red-capped mangabeys (Cercocebus torquatus torquatus)," Applied Animal Behaviour Science, vol. 124, no. 1-2, pp. 68-74, 2010.

[17] G. J. Mason, “Stereotypies: a critical review," Animal Behaviour, vol. 41, no. 6, pp. 1015-1037, 1991.

[18] D. S. Mills, "Repetitive movement problems in the horse," in The Domestic Horse, The Origins, Development and Management of Its Behaviour, S. M. McDonnell, Ed., pp. 212-227, Cambridge University Press, Cambridge, UK, 2005.

[19] G. Waring, Horse Behavior, Noyes Publications/William Andrew, New York, NY, USA, 2nd edition, 2003.

[20] P. D. McGreevy, P. J. Cripps, N. P. French, L. E. Green, and C. J. Nicol, "Management factors associated with stereotypic and redirected behaviour in the thoroughbred horse," Equine Veterinary Journal, vol. 27, no. 2, pp. 86-91, 1995.

[21] J. J. Cooper, L. McDonald, and D. S. Mills, "The effect of increasing visual horizons on stereotypic weaving: implications for the social housing of stabled horses," Applied Animal Behaviour Science, vol. 69, no. 1, pp. 67-83, 2000.

[22] M. Hausberger, C. Bruderer, N. L. Scolan, and J. S. Pierre, "Interplay between environmental and genetic factors in temperament/personality traits in horses (Equus caballus)," Journal of Comparative Psychology, vol. 118, no. 4, pp. 434-446, 2004.

[23] M. Hausberger, C. Muller, and C. Lunel, "Does work affect personality? A study in horses," PLoS ONE, vol. 6, no. 2, 2011.

[24] M. Hausberger, E. Gautier, C. Müller, and P. Jego, "Lower learning abilities in stereotypic horses," Applied Animal Behaviour Science, vol. 107, no. 3-4, pp. 299-306, 2007.

[25] M. Hausberger, E. Gautier, V. Biquand, C. Lunel, and P. Jégo, "Could work be a source of behavioural disorders? a study in horses," PLoS ONE, vol. 4, no. 10, Article ID e7625, 2009.

[26] J. Altmann, "Observational study of behavior: sampling methods," Behaviour, vol. 49, no. 3-4, pp. 227-267, 1974.

[27] S. Siegel and J. Castellan, Nonparametric Statistics for the Behavioral Sciences, McGraw-Hill, New York, NY, USA, 2nd edition, 1988.

[28] R. Bergeron, A. J. Badnell-Waters, S. Lambton, and G. Mason, "Stereotypic oral behaviour in captive ungulates: foraging, diet and gastrointestinal functions," in Stereotypic Animal Behaviours-Fundamentals and Applications to Welfare, G. Mason and J. Rushen, Eds., pp. 19-57, CABI, Oxford, UK, 2nd edition, 2006.

[29] B. Holmgren, R. Budelli, R. Urba-Holmgren et al., "Food anticipatory yawning rhythm in the rat," Acta Neurobiologiae Experimentalis, vol. 51, no. 3-4, pp. 97-105, 1991. 
[30] P. Mormède, S. Andanson, B. Aupérin et al., "Exploration of the hypothalamic-pituitary-adrenal function as a tool to evaluate animal welfare," Physiology and Behavior, vol. 92, no. 3, pp. 317-339, 2007.

[31] F. Ödberg, "Abnormal behaviours: stereotypies," in Proceedings of the 1st World Congress on Ethology Applied in Zootechnics, Garci, Ed., pp. 475-480, Industrias Graficas Espana, Madrid, Spain, 1978.

[32] J. Rushen and G. Mason, “A decade-or-more's progress in understanding stereotypic behaviour," in Stereotypic Animal Behaviours-Fundamentals and Applications to Welfare, J. Rushen and G. Mason, Eds., pp. 1-17, CABI, Oxford, UK, 2nd edition, 2006.

[33] A. Troisi, F. Aureli, G. Schino, F. Rinaldi, and N. Deangelis, "The influence of age, sex, and rank on yawning behavior in 2 species of macaques (Macaca-fascicularis and M-Fuscata)," Ethology, vol. 86, pp. 303-310, 1990.

[34] B. L. Deputte, J. Johnson, M. Hempel, and G. Scheffler, "Behavioral effects of an antiandrogen in adult male rhesus macaques (Macaca mulatta)," Hormones and Behavior, vol. 28, no. 2, pp. 155-164, 1994. 

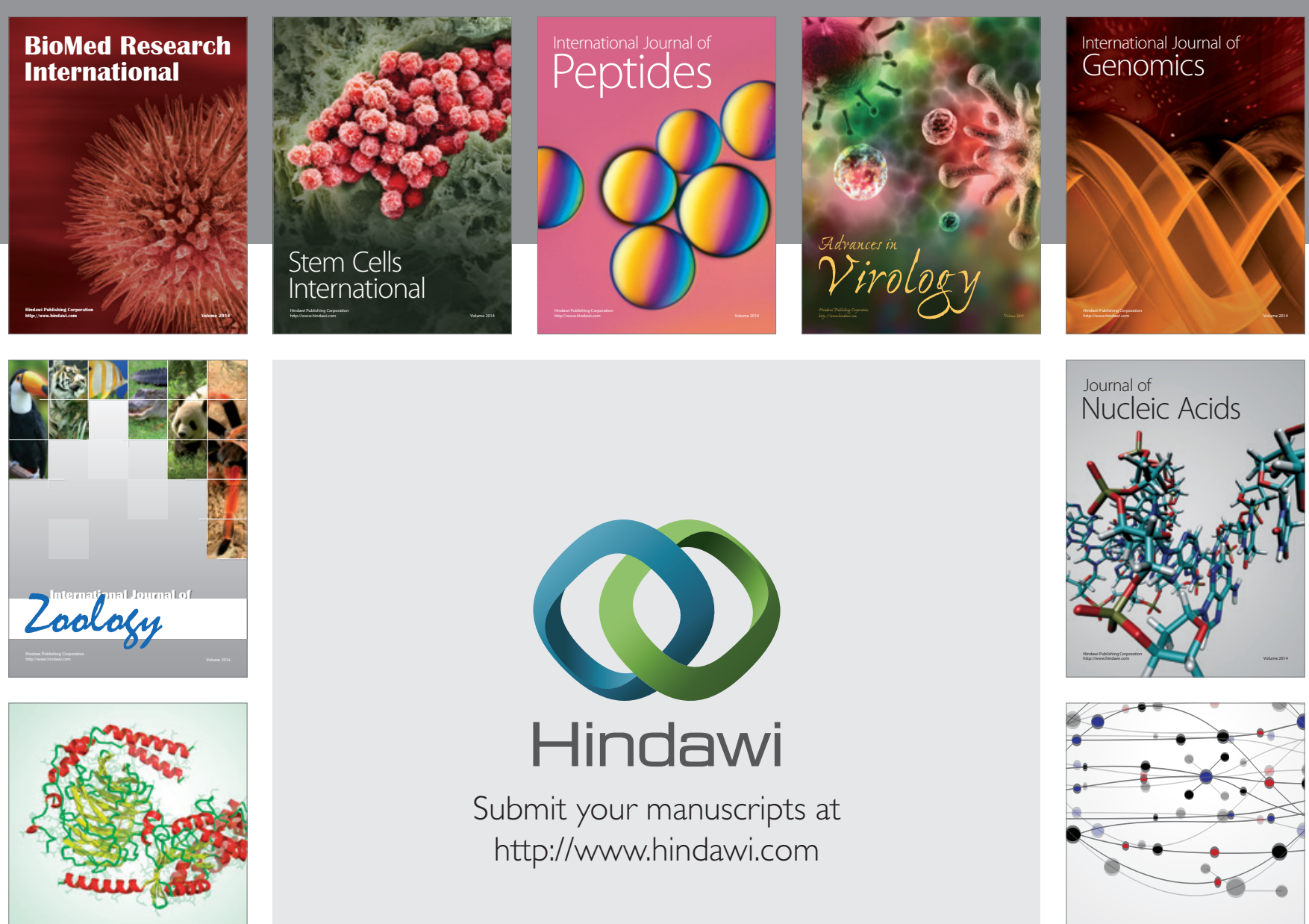

Submit your manuscripts at

http://www.hindawi.com

Signal ${ }^{\text {Jumal }}$ Transduction
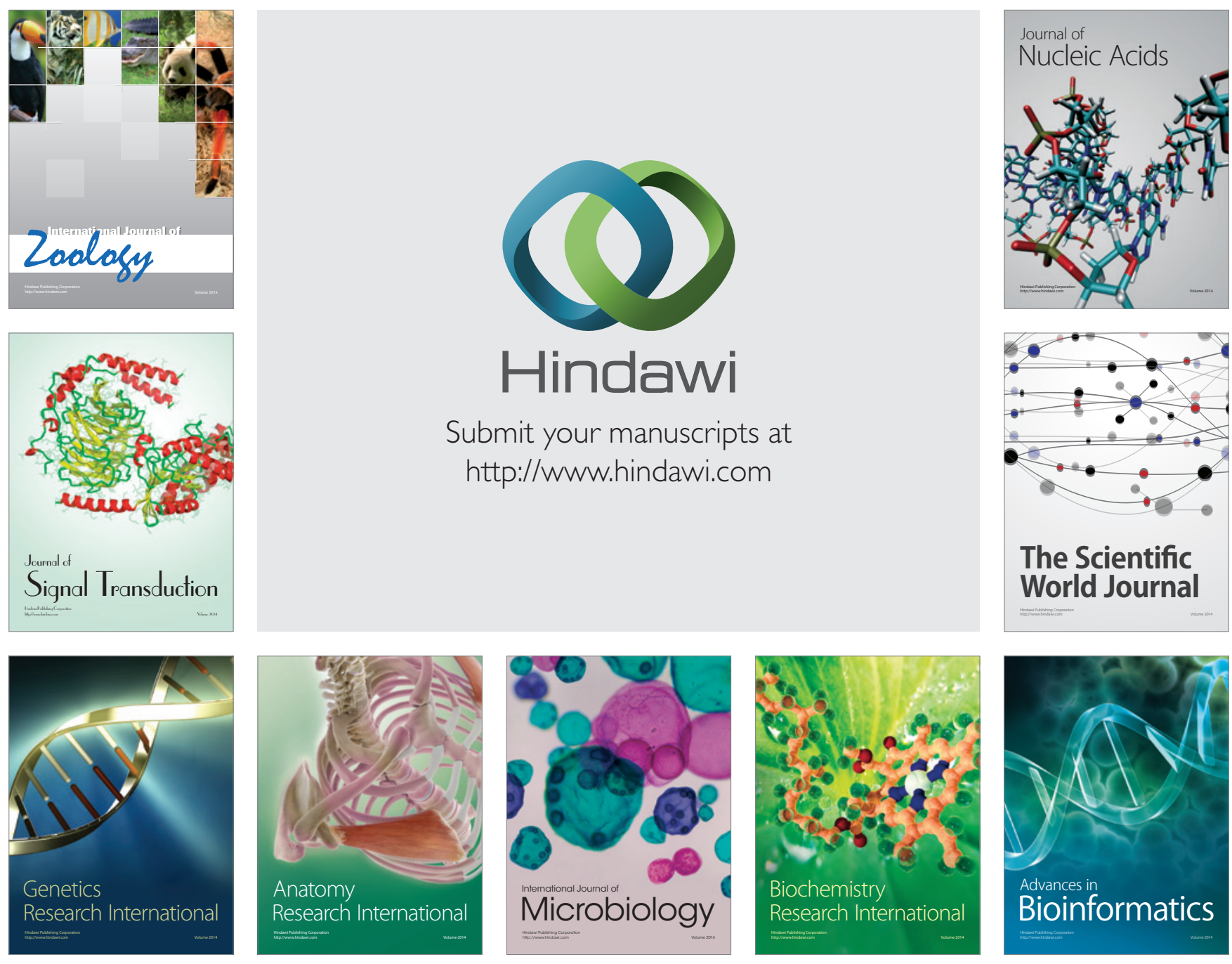

The Scientific World Journal
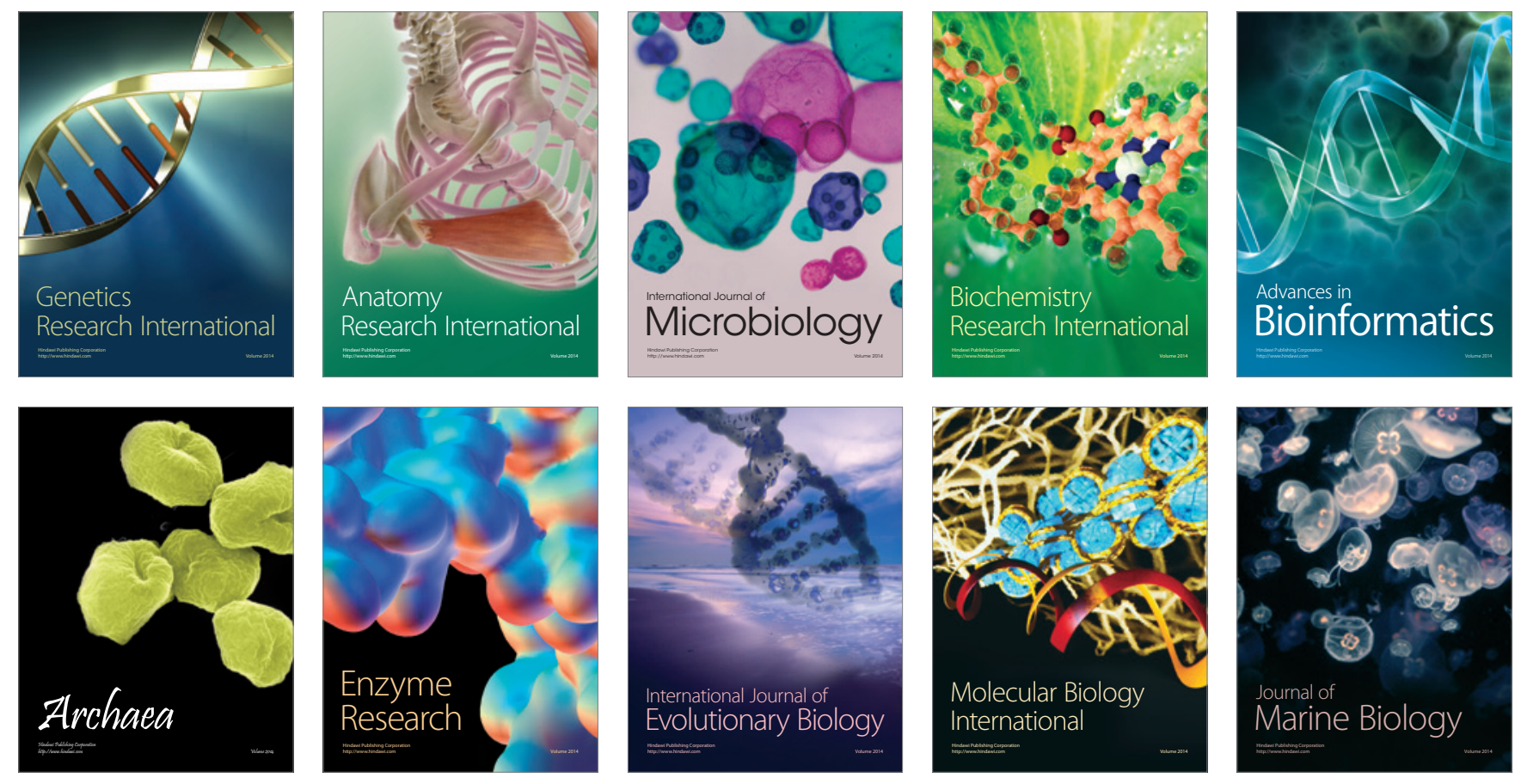